\title{
Attitudes of residents in the Tokyo Bay area toward flood hazards
}

\author{
H. Gotoh ${ }^{1}$, H. Oshiki ${ }^{2}$, Y. Maeno ${ }^{1} \&$ T. Takezawa ${ }^{1}$ \\ ${ }^{1}$ Department of Civil Engineering, \\ College of Science and Technology, Nihon University, Japan \\ ${ }^{2}$ Japan Institute of Construction Engineering, Japan
}

\begin{abstract}
There have been many recent reports of flood disasters from around the world. Many countries attempt to prepare for disaster situations, but one difficulty that exists in terms of preparing for flooding is that despite the level of flood hazard that may exist, many people living within river basins are unable to leave their homes or seek to return to their homes as soon as the immediate danger has passed.

We distributed a questionnaire concerning flood hazards to residents within the basin of the Arakawa River in the old-town area of Tokyo, Japan. The Arakawa River, which drains into Tokyo Bay, was planned in 1911 with the aim of protecting the citizens of Tokyo from flooding; it was completed in 1930. All local residents are assigned a specified evacuation area by the local administrative body.

The questionnaire was given to a random sample of about 1000 people living along the Arakawa River. The obtained answers make it clear that many people living along the river are unaware of their designated evacuation area in the case of flooding. This is an issue that must be dealt with by administrative guidance and efforts on the part of the residents. Consequently, the local administrative body must ensure that residents are well informed in terms of hydrological information and the locations of areas that provide refuge from flooding.

Keywords: flood hazard, attitude survey, Arakawa River, flood, tidal wave, tsunami.
\end{abstract}

\section{Introduction}

The Tokyo metropolitan area is the largest urban area in Japan. The area contains a high density of both residents and property; however, many rivers, such as the 
Arakawa, Tamagawa, and Edogawa rivers, flow through metropolitan Tokyo. Thus, the Tokyo metropolitan area faces the risk of destructive flooding disasters. This is particularly the case along the Arakawa River, where subsidence means that the ground level is lower than sea level and lower than the surface of the river. Accordingly, this area is now referred to as a "zero meter area". The major concern is that if the levee of the Arakawa River is broken the area will sustain extensive flood damage. Despite this risk, many people live in the area protected by the high and solid levees, and these residents wish to have their own houses.

There has been a recent trend toward heavier rainfall in the Tokyo area; consequently, there is apprehension concerning flood hazards in the area. If a powerful typhoon hits the Tokyo metropolitan area, it is possible that a large tidal wave will strike the Tokyo Bay area. As a result of such extraordinary weather, it is predicted that the Tokyo urban area will be subjected to a flood disaster. It has been inferred that the increasing frequency of heavy rain and powerful typhoons is related to the influence of global warming.

Civil services currently distribute a map to residents that outlines the hazard area should the levee break or tidal waves strike; this is intended to raise the awareness of flood hazards of residents along the Arakawa River.

The present paper details the results of a survey of residents along the Arakawa River that questioned their attitudes toward flood hazards. The survey results reveal that the attitudes of residents vary as a function of residential area and age, among other factors. Furthermore, we conducted a cluster analysis of the survey results and classified different areas on the basis of the analysis. We propose that measures against flooding should reflect the characteristics of each of these areas.

\section{Description of the "Arakawa drain" and its basin}

The Arakawa River flows from Mt. Kobushigadake to Tokyo Bay through Saitama Prefecture and the Tokyo metropolitan area (Figure 1) [1]. Downstream of Iwabuti Lock (Figure 2), the Arakawa River divides into two flows that are termed the Arakawa and Sumida rivers. In this downstream section, the Arakawa River is correctly called "Arakawa drain", which is the artificial channel that was constructed to protect the old part of Tokyo from flood disasters. The Arakawa drain was constructed from 1911 to 1924 , and is $22 \mathrm{~km}$ in length and $500 \mathrm{~m}$ in width. In the present day, the Arakawa drain does not resemble an artificial channel, as the region along the Arakawa drain has a rich natural environment (Figure 4).

There are seven wards within the drainage basin of the Arakawa drain in the Tokyo metropolitan area: Sumida, Kita, Arakawa, Adachi, Katsushika, Edogawa, and Koto (Figure 2) [2-9]. The Sumida, Kita, Adachi, Arakawa, and Katsushika Wards can be regarded as the old part of Tokyo, whereas Edogawa and Koto Wards are largely built on reclaimed ground and are regarded as a new part of Tokyo. Table 1 shows the populations and recent population-growth ratios for these wards. About $30 \%$ of the citizens of the Tokyo special wards are concentrated in this area, and the population of the area continues to increase. 


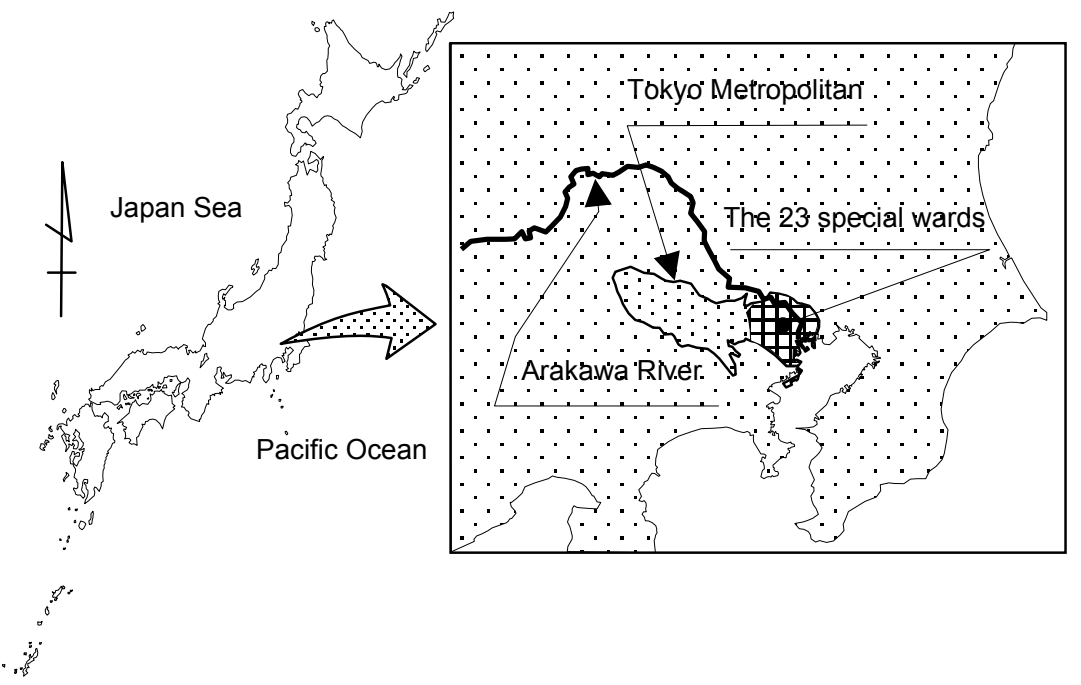

Figure 1: $\quad$ Location map of the study area.

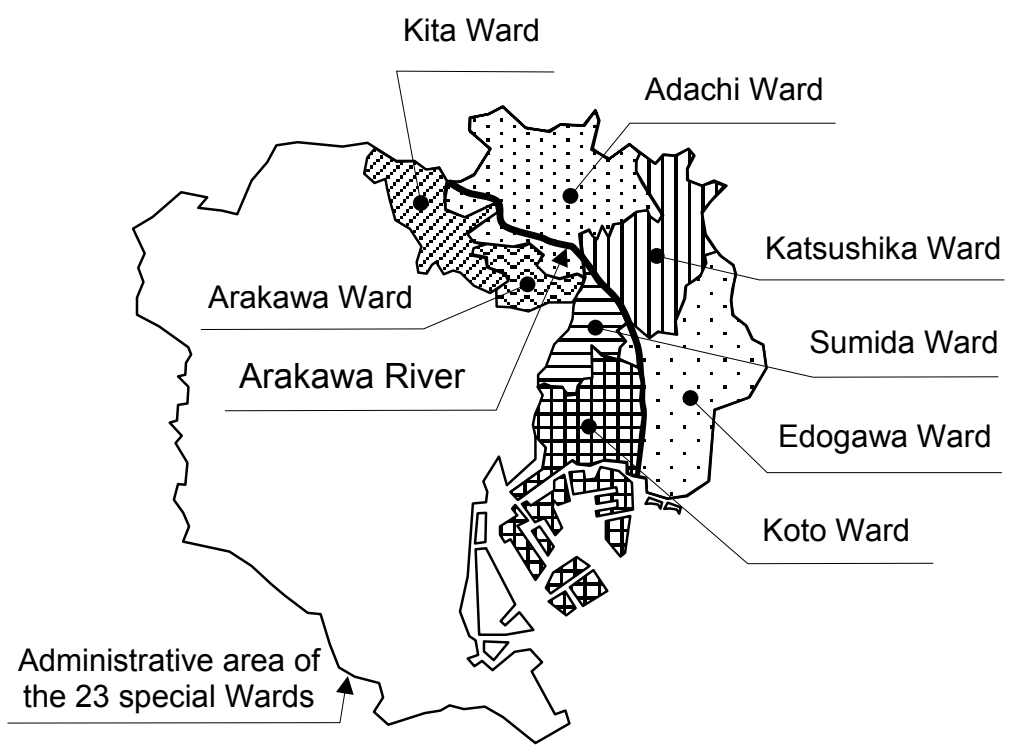

Figure 2: $\quad$ Location of the drainage basin of Arakawa drain.

Ground level in this area is lower than the water surface within the Arakawa drain. This low area, called the 'zero meter area', extends over $84.9 \mathrm{~km}^{2}$ (Figure 3). Land subsidence has occurred in this area since the early 20th century because large amounts of groundwater have been drawn from wells to use as industrial water. Figure 5 shows temporal changes in accumulated subsidence at representative points. The largest amount of subsidence total about $4.5 \mathrm{~m}$. 


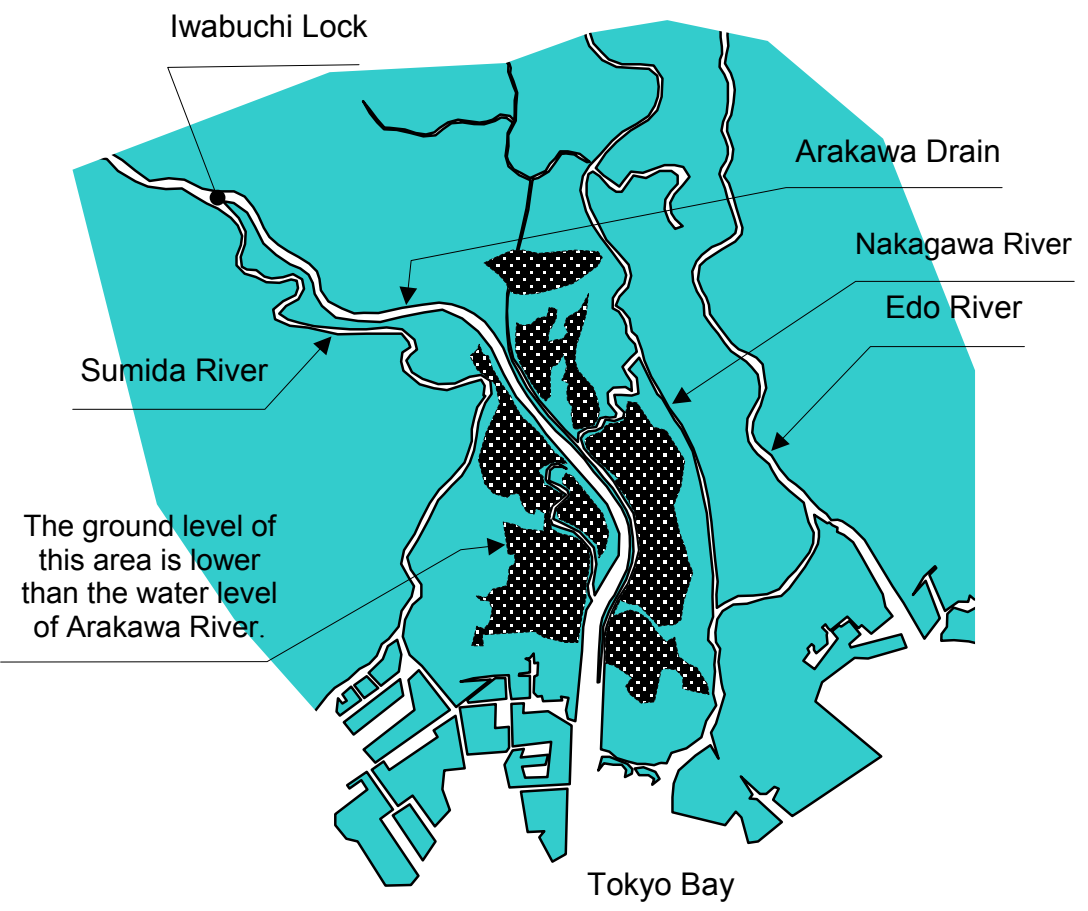

Figure 3: Arakawa drain and its associated flood hazard area (zero meter area).

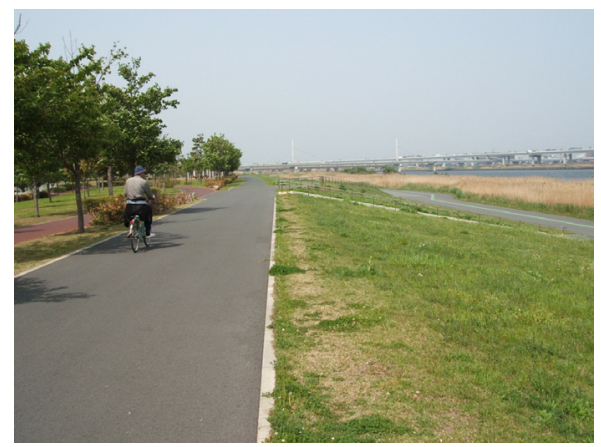

Figure 4: View from the super-levee along the Arakawa Drain, showing its rich natural environment (Hirai area).

The subsidence has now ceased because of government regulations that prohibit the drawing of groundwater. For this reason, government departments have constructed hazard maps to distribute to residents to inform them of the flood hazard. 
Table 1: Population and population growth in the area along the Arakawa drain.

\begin{tabular}{|c|c|c|}
\hline Area & $\begin{array}{c}\text { Population growth } \\
\text { ('05/'04)(\%) }\end{array}$ & $\begin{array}{c}\text { Population ('05) } \\
\text { (persons) }\end{array}$ \\
\hline Adachi Ward & 100.2 & 624,548 \\
\hline Kita Ward & 100.2 & 316,202 \\
\hline Arakawa Ward & 100.8 & 177,216 \\
\hline Sumida Ward & 100.9 & 230,996 \\
\hline Koto Ward & 102.4 & 420,831 \\
\hline Katsushika Ward & 100.4 & 424,801 \\
\hline Edogawa Ward & 100.7 & 653,882 \\
\hline
\end{tabular}

$(8,483,050$ persons live in the 23 special Wards in 2005).

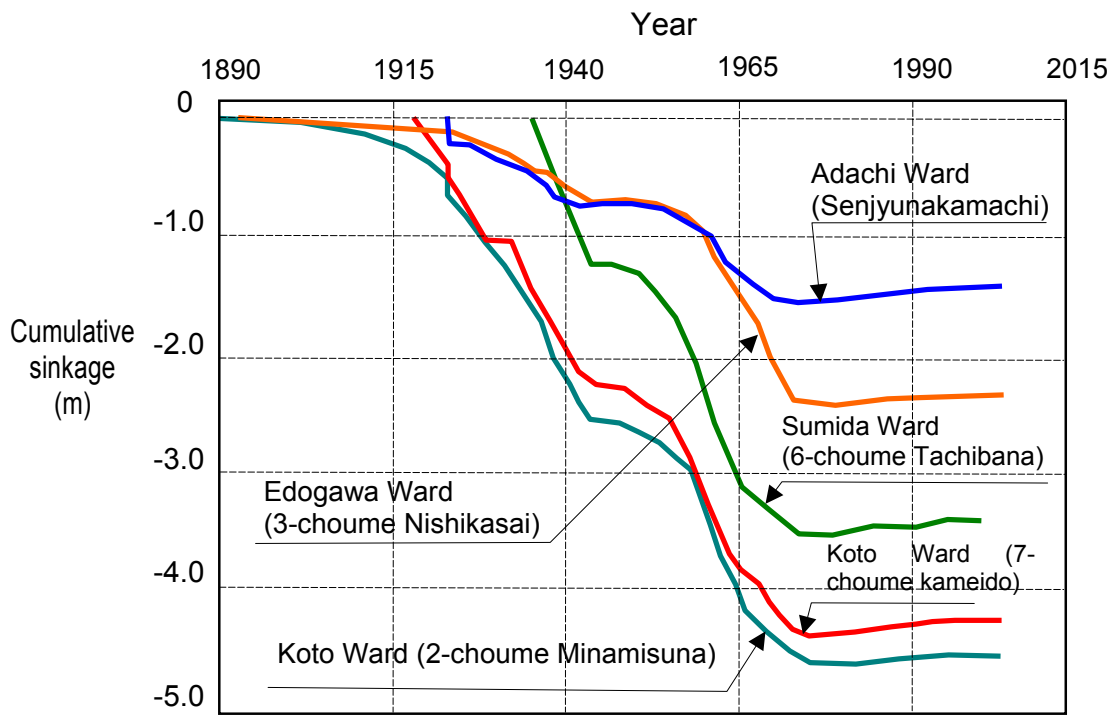

Figure 5: Temporal trends in accumulated land subsidence within the study area.

\section{Summary description of the attitude survey of residents living along the Arakawa drain}

Table 2 shows the content of the attitudes questionnaire sent to residents along the Arakawa drain. We distributed 4000 questionnaires to residents living within the eight areas along the Arakawa drain basin shown in Figure 6. We delivered the questionnaires to detached houses only: residents living in apartment houses were not targeted in this study. An average of $23 \%$ of residents in the different areas returned the completed questionnaire (Table 3 ). 
Table 2: $\quad$ Contents of the questionnaire supplied to residents.

Please answer the questions below:

1. Sex? (Male or Female?)

2. Age? ( )

3. Job? ( )

4. Address? ( )

5. Did you know that the Arakawa River is an artificial channel? (Yes or No)

6. Are you in danger of flooding from the Arakawa River? (Yes or No)

7. Is the levee height a source of worry for you? (Yes or No)

8. Have you walked on the levee? (Yes or No)

9. Do you think that the width of the levee is sufficient? (Yes or No)

(for Higashisuna and Adachi areas)

9. Do you think that the height and width of the levees are sufficient? (Yes or No)

(for Kasai, Matsushima, Yotsugi, Hirai, Sumida, and Senjyu areas)

10. Do you think that the height of the levee is sufficient? (Yes or No) (for Higashisuna and Adachi areas)

10. Can you approach the riverside easily? (Yes or No) (for Kasai, Matsushima, Yotsugi, Hirai, Sumida, and Senjyu areas)

11. Has your property ever been damaged by flood? (Yes or No)

12. Are you in danger of tidal waves (Tsunami)? (Yes or No)

13. Do you think that the levee is sufficiently strong should an earthquake occur? (Yes or No)

14. In case of flooding, do you know where your designated evacuation area is? (Yes or No)

15. Do you think the evacuation area is safe? (Yes or No)

16. Is the evacuation area far from your place of residence? (Yes or No)

17. Do you think you will move to another area in the future? (Yes or No)

18. Do you think your residential area has a good environment? (Yes or No)

19. Do you think there are enough convenient facilities (train station, shops, and so on) for living in your residential area? (Yes or No)

20. Do you have opinions on disaster prevention measures of Arakawa River? (Yes or No)

Table 3: $\quad$ Collection ratio for each area.

\begin{tabular}{|c|c|c|c|}
\hline \multicolumn{2}{|c|}{ Right basin of Arakawa drain } & \multicolumn{2}{|c|}{ Left basin of Arakawa drain } \\
\hline Area & Collection ratio & Area & Collection ratio \\
\hline $\begin{array}{c}\text { Higashisuna } \\
\text { (Koto Ward) }\end{array}$ & $\begin{array}{c}20.0 \% \\
(100 \text { persons) }\end{array}$ & $\begin{array}{c}\text { Kasai } \\
\text { (Edogawa Ward) }\end{array}$ & $\begin{array}{c}19.6 \% \\
(98 \text { persons) }\end{array}$ \\
\hline $\begin{array}{c}\text { Hirai } \\
\text { (Edogawa Ward) }\end{array}$ & $\begin{array}{c}26.0 \% \\
(130 \text { persons) }\end{array}$ & $\begin{array}{c}\text { Matsushima } \\
\text { (Edogawa Ward) }\end{array}$ & $\begin{array}{c}22.8 \% \\
(114 \text { persons) }\end{array}$ \\
\hline $\begin{array}{c}\text { Sumida } \\
\text { (Sumida Ward) }\end{array}$ & $\begin{array}{c}24.6 \% \\
(123 \text { persons) }\end{array}$ & $\begin{array}{c}\text { Yotsugi } \\
\text { (Katsushika Ward) }\end{array}$ & $\begin{array}{c}23.4 \% \\
(117 \text { persons) }\end{array}$ \\
\hline $\begin{array}{c}\text { Senjyu } \\
\text { (Adachi, Arakawa, } \\
\text { and Kita Wards) }\end{array}$ & $\begin{array}{c}30.0 \% \\
(150 \text { persons) }\end{array}$ & $\begin{array}{c}\text { Adachi } \\
\text { (Adachi Ward) }\end{array}$ & $\begin{array}{c}22.8 \% \\
(114 \text { persons) }\end{array}$ \\
\hline
\end{tabular}

(We distributed 500 questionnaires to each of the 8 areas shown in Figure 5). 


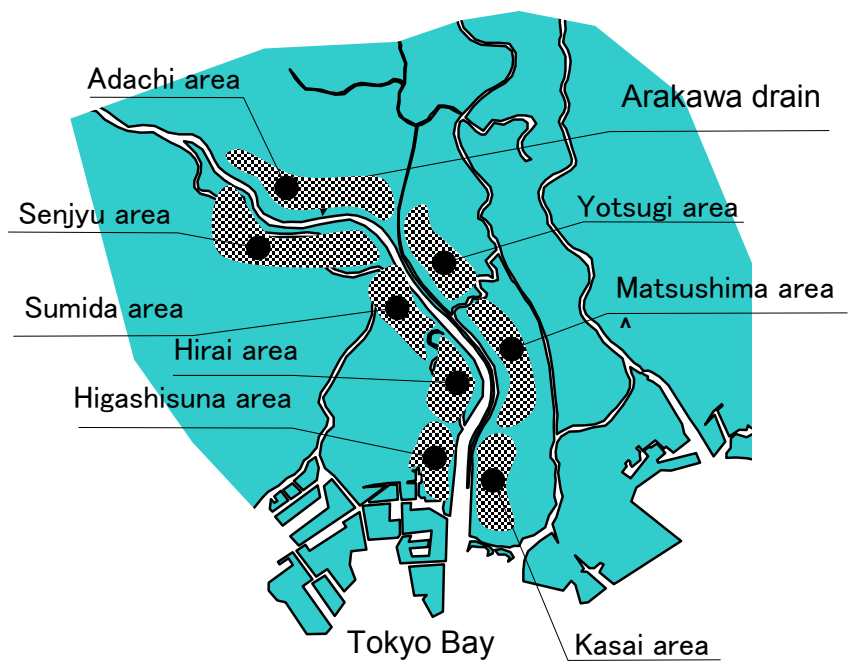

Figure 6: Areas in which the questionnaires were distributed.

\section{Summary of the results of the attitude survey}

Figures 7 and 8 show the proportions of "YES" answers to the survey questions in terms of survey area, age, and sex. Male and female respondents provided similar answers to each question. Unfortunately, that fact that we distributed questionnaires to the owners of detached houses means that most of the respondents are elderly. Figures 7 and 8 show that contrasting answers were obtained for Qs. 5, 6, 7, 11, 15, 16, 17, 18, 19, and 20.

In terms of the responses to Q. 5 shown in Figures 7 and 8, it is clear that most of the residents are aware that the Arakawa River flows within an artificial channel, but the proportion of residents who are unaware of this fact increases downstream, as the downstream area is a relatively young district. In terms of Qs. 6 and 11, which ask if the area has been previously damaged by flooding, most of the residents state that they are aware of the risk of a flood disaster. Questions 17, 18, and 19 reveal that despite the general awareness of this risk, most of the residents wish to continue to live the area.

The answers to Q. 7 differ according to the type of levee constructed in front of the residential area. The residents of the Adachi, Senjyu, Sumida, and Hirai areas are unafraid of a flooding disaster relative to the degree of fear expressed in other areas. This is especially true in the Sumida and Hirai areas, as a super-levee has been constructed in these areas (Figure 4) and the residents can easily approach the river via a recreation area, walk along the river, and play sports within view of the flowing water. We define a "super-levee" as a river embankment with a broad width that can withstand overflow, thereby preventing damage to the dike and associated flooding. However, not all of the traditional levees in the area have been upgraded to super-levees. In the Kasai, Higashisuna, Matsushima, and Yotsugi areas, the flowing water and riverside land are not 
easily seen from the protected lowland area. The residents who live in these areas have a keen awareness of the potential risk of flooding. Regarding Qs. 15, 16, and 20, the residents know of the local site that provides refuge from flooding, and they consider that the site is safe. It is clear from the responses to Q. 20 that some of the residents will travel to the refuge site if flooding occurs.

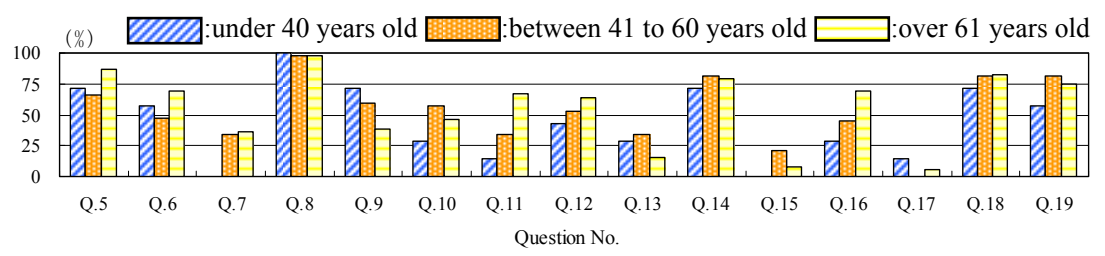

(a) Higashisuna area

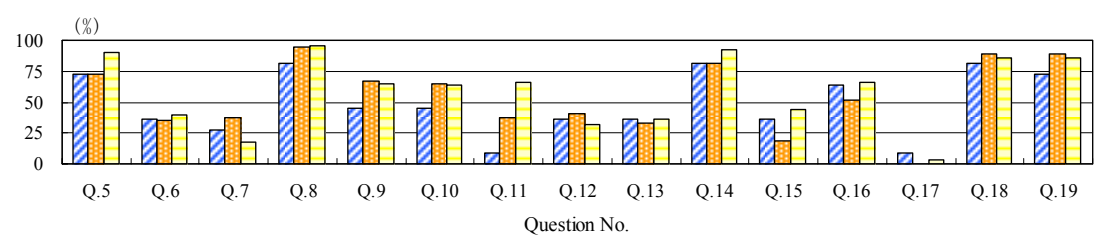

(b) Hirai area

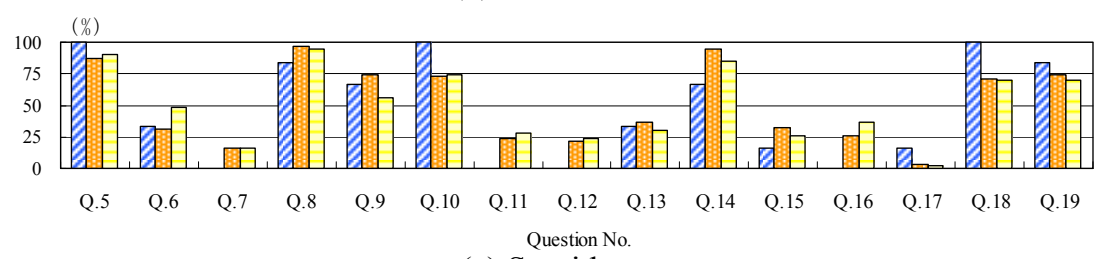

(c) Sumida area

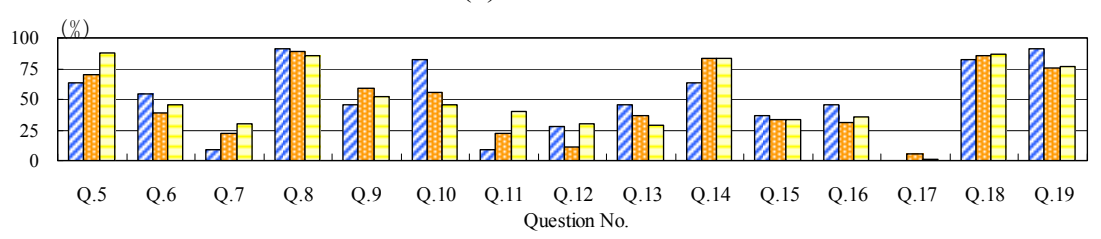

(d) Senjyu area

Figure 7: Result of questionnaires delivered to the right-hand side of the drain.

\section{Cluster analysis of the results of the attitude survey}

We conducted a cluster analysis of the responses of residents in each of the surveyed areas. Cluster analysis encompasses a number of different algorithms and methods for grouping similar objects into respective categories [10]. Figure 9 shows the hierarchical tree of the cluster analysis undertaken in this study. To perform the cluster analysis, the answers to Qs. 5-19 (excluding Q. 10) were used as predictor valuables. The horizontal axis in Figure 9 shows linkage distance, while the vertical axis shows the three identified groups (Groups. 1-3). 


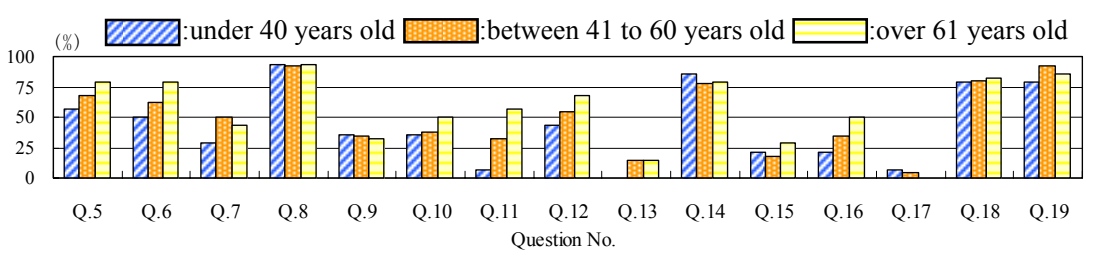

(a) Kasai area

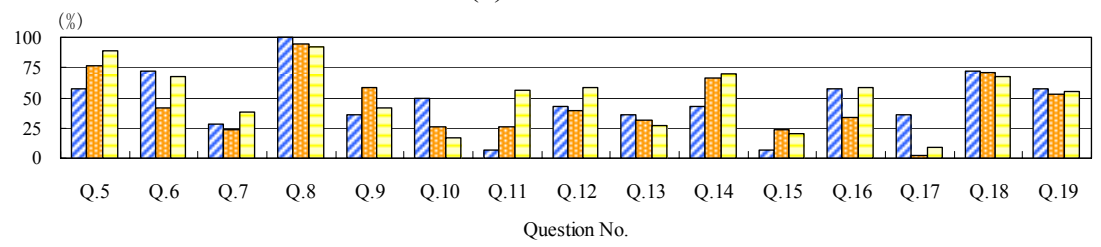

(b) Matsushima area

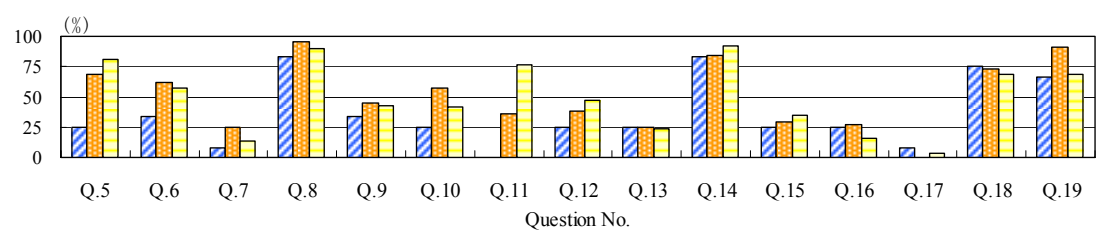

(c) Yotsugi area

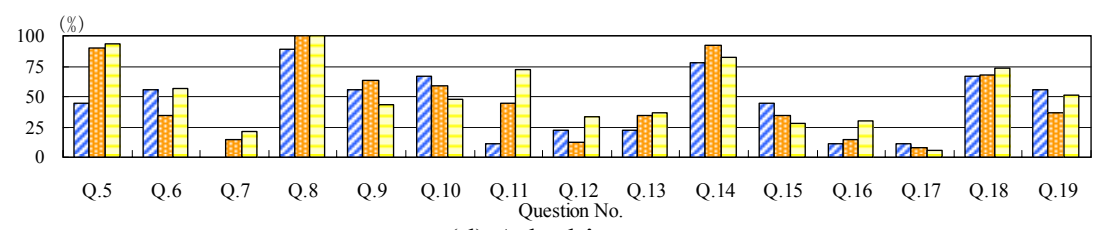

(d) Adachi area

Figure 8: Result of questionnaires delivered to the left-hand side of the drain.

It is apparent that the attitudes among residents can be divided into upstream (Gs. 2 and 3) and downstream (G. 1) groups. Within the upstream group, we also recognize differences between the results for the right-hand and left-hand sides of the basin. We consider that these differences reflect the degree of residents' fear of a flooding disaster. The residents in G. 1 are afraid of a flooding disaster and have a keen awareness of flood hazards relative to those in Gs. 2 and 3. This is because the residents of Gs. 2 and 3 have an affinity for the river, as they are able to approach waterside areas with ease; therefore, they do not fear a flooding disaster.

To effectively enlighten the residents of the risk of a flooding disaster, it is necessary to consider the characteristics of each residential area.

\section{Conclusion}

In this study, we conducted a survey of the attitudes toward flood hazards of residents within the drainage basin of the Arakawa drain. We also conducted a cluster analysis of the survey results. 


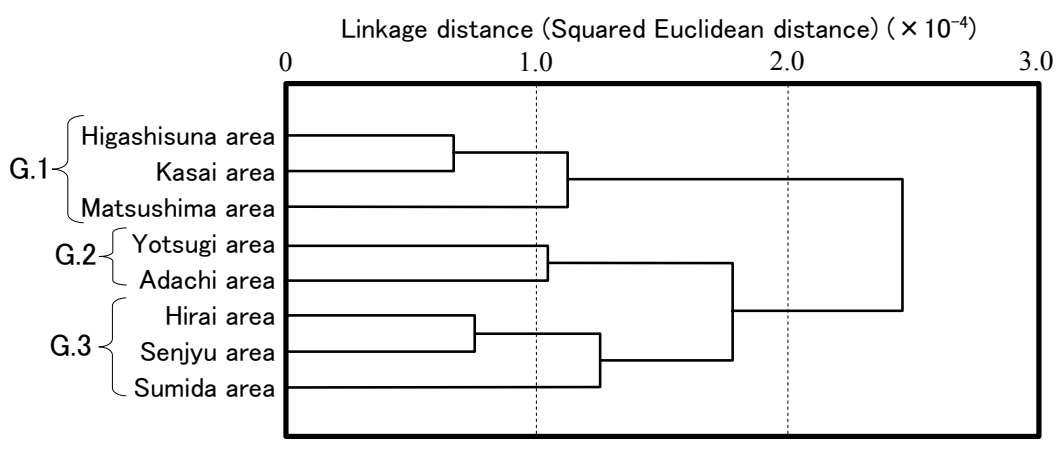

Figure 9: Results of cluster analysis.

The results demonstrate that the respondents' attitudes toward flood hazards differ among the different survey areas. Residents are more afraid of flooding disasters in the new part of Tokyo, in the downstream area, than in the older upstream area. We also recognized differences in the attitudes toward flood hazards in the right-hand and left-hand basins of the upstream area. We consider that the attitudes toward flood hazards depend upon the affinity that residents have for the river, which in turn is related to the ease with which residents can approach the riverside area. If the flowing water cannot be seen from the protected lowland area, as determined by the type of levee, the residents are more likely to fear a flood disaster.

While it goes without saying that the maintenance of infrastructure along the rivers must continue to be performed, it is also necessary to enlighten residents of the nature of flood hazards in the area. To do this, it is important to consider the individual characteristics of the different residential areas.

\section{References}

[1] Ministry of Land, Infrastructure and Transport, Kanto Regional Development Bureau, Arakawa-karyu Office, www.ara.go.jp/

[2] Tokyo Metropolitan Government, www.kensetsu.metro.tokyo.jp/

[3] Koto City Office, www.city.koto.lg.jp/

[4] Edogawa City Office, www.city.edogawa.tokyo.jp/

[5] Katsushika City Office, www.city.katsushika.lg.jp/

[6] Sumida City Office, www.city.sumida.lg.jp/

[7] Adachi City Office, www.city.adachi.tokyo.jp/

[8] Arakawa City Office, www.city.arakawa.tokyo.jp/

[9] Kita City Office, www.city.kita.tokyo.jp/

[10] www.statsoft.com/textbook/stcluan.html 